Contents list available at IJRED website

Int. Journal of Renewable Energy Development (IJRED)

Journal homepage: http://ejournal.undip.ac.id/index.php/ijred

\title{
The Costs of Producing Biodiesel from Microalgae in the Asia-Pacific Region
}

\author{
G.J. Griffin ${ }^{\mathrm{a}^{*}, \text { D.F. Batten }}{ }^{\mathrm{b}}$, T. Beerb and P.K. Campbellc \\ a School of Civil, Environmental and Chemical Engineering, RMIT University, Melbourne, AUSTRALIA \\ ${ }^{b}$ CSIRO Marine and Atmospheric Research, Aspendale, AUSTRALIA \\ c University of Tasmania, Hobart, AUSTRALIA
}

\section{Article history:}

Received Sept 8, 2013 Received in revised form Sept 27,2013 Accepted October 3, 2013 Available online

\begin{abstract}
Capital and operating cost estimates for converting microalgae to oil or biodiesel are compared. These cost comparisons are based on Australian locations, which are expected to fall at the lower end of the cost spectrum in the Asia-Pacific Region and other parts of the world. It is assumed that microalgae are grown in a concentrated saltwater medium in raceway ponds, then are harvested, dewatered and the oil is extracted and converted to biodiesel by transesterification. The size of the desired pond system affects the number of potential locations due to constraints in resource availability. Cost estimates vary significantly due to differences in the assumed oil productivity, the harvesting equipment and the method of converting residual biomass to electric power. A comparison is made with recent cost estimates from other parts of the world, in which the expected costs of microalgae oil production from a number of publicly available sources lay between 0.34-31.0 USD/L. The resulting cost estimates of between 1.37-2.66 USD/L are at the lower end of this scale, thereby confirming that Australia has the potential to be a low-cost producer of algal oil and biodiesel in the Asia-Pacific Region. It was significant that, despite similar assumptions for the microalgae-to-oil process, cost estimates for the final biodiesel or oil price differed by a factor of 2 . This highlights the high degree of uncertainty in such economic predictions.
\end{abstract}

Keywords: Asia-Pacific region; biodiesel; economics; microalgae

\section{Introduction}

The exploitation of microalgae biomass to produce sustainable biofuels and, thereby, supplant conventional fossil fuels has attracted much attention in recent years. Compared to other, second generation biofuel sources, microalgae have considerable advantages - they can grow rapidly; yield more biofuel per hectare than terrestrial plants; contain little or no toxic substances; are biodegradable; can generate relatively low green-house gas (GHG) emissions, and do not compete directly with food production. However, there is a large degree of uncertainty in the economic feasibility of biofuel production as the efficient cultivation of microalgae is constrained by the availability of necessary resources. The large-scale cultivation of microalgae requires:

- a robust microalgae species that grows rapidly, is easily harvested and contains large amounts of extractable oil;

- year round warm sunlight and insolation;

- a sustainable source of nutrients (primarily carbon, nitrogen and phosphorous);

- a sustainable water supply, and;

- large areas of flat land, preferably in arid regions unsuitable for agriculture.

Van Harmelen \& Oonk (2006) examined the availability of the latter four resources on a global scale. The constraints used were:

- that the growing regions would need to be in the area between $37^{\circ}$ north and south latitude

\footnotetext{
* Corresponding author: Tel: +61 399252200

E-mail: gregory.griffin@ rmt.edu.au
} 
(to provide the necessary sunlight and temperatures).

- that land altitude should be less than 500m (an indication of the flatness suitable for growing microalgae in ponds)

- that a population density of greater than 25 persons $/ \mathrm{km}^{2}$ was necessary to supply nutrients and water (water and nitrogen/phosphorus nutrients from treatment plants, carbon dioxide from power plant flue gases), but that the high population density areas be close to low population density areas (i.e. less than 25 persons $/ \mathrm{km}^{2}$ ) where land is available for large-scale ponds at low cost.

Van Harmelen \& Oonk (2006) identified significant portions of inland China, South-East Asia and India where all potential resources were co-located so as to be suitable for microalgae production.

Using the resource constraints identified by van Harmelen \& Oonk (2011); Batten et al. (2011) estimated that biodiesel sourced from microalgae could replace less than $2 \%$ of current fossil diesel usage in APEC countries (on average). However, by relaxing some of these constraints, i.e. assuming that nitrogen, phosphorous and water may be recycled, so that carbon is the only limiting factor, these authors found that more than $10 \%$ of their diesel needs could be satisfied from locally grown microalgae in Asian nations such as the Peoples' Republic of China, Indonesia, Chinese Taipei and Thailand.

Potentially, the production of biodiesel from microalgae may be further increased if water used to grow the microalgae is not limited to wastewaters. In those countries where the climate is conducive to high microalgal growth rates, fresh water resources are, generally, limited as they are needed for agriculture, human consumption, or to maintain sufficient flows in rivers so as to maintain the viability of the indigenous environment. Therefore, the only alternative source of water is seawater. Cultivation using this water resource is likely to occur close to the coastline to minimise costs of water transport. Although coastal land near cities is mostly expensive, Australia is one of the few locations in the Asia-Pacific Region in which significant amounts of marginal coastal land has been identified (Regan \& Gartside 1983). Chile, Mexico and the United States are other possibilities. This suggests an alternative strategy for Asian nations interested in using algal biodiesel, namely the importation of that biodiesel produced from microalgae grown in Australia or the Americas.

Australia has been recognized as an ideal location for growing microalgae. Pilot plant facilities for the production of oil from microalgae have been built in Northern Australia (by Aurora Algae, Muradel and MBD) and a large production facility is under construction in New South Wales (by Algae Tech). However, the actual costs of oil production from these facilities have not been reported.
The purpose of this paper is to explore how sensitive the costs involved in the conversion of microalgae to biodiesel are likely to be, based on the production of biodiesel under favourable conditions in Australia. The cost comparisons are based on estimates found in Griffin \& Batten (2009) and Campbell et al. $(2008,2011)$ in which the microalgae ponds were located to take advantage of available resources. The economic predictions are compared with several independent sets of predictions derived from sources in other nations (Pienkos 2008; Alibi et al. 2009; USDoE 2009; Stephens et al. 2010; Gallagher 2011; Amer et al. 2011).

In Campbell et al. (2008, 2011)- hereafter referred to as Campbell et al.- the costs used were largely based on those given by Benemann \& Oswald (1996), adjusted to values for 2008. The study by Griffin and Batten (2009) - hereafter referred to as Griffin and Batten was drawn from a wider field of available literature. In both studies, the economic feasibility calculations were for the growth of microalgae in raceway ponds in which carbon to feed the microalgae was supplemented (i.e. additional to that present as $\mathrm{CO}_{2}$ in the atmosphere). Both sources reported the costs of growing and harvesting the microalgae, followed by extracting the oil and then converting the oil to biodiesel. Each source explores several scenarios, such as how the supplementary carbon is sourced. Although some assumptions differed, one set of scenarios from each source was similar. This scenario $\left(7.5 \mathrm{~g} \mathrm{~m}^{-2}\right.$ day $^{-1}$ oil production rate, refer next section) was found to be the most economic process according to both sources.

\section{The Microalgae to Biodiesel Production Route}

The studies report an economic cost for producing microalgae using sea water as the growth medium, with carbon supplementation by bubbling of flue gases sourced from nearby power stations (they also include scenarios using high concentration $\mathrm{CO}_{2}$ to supplement carbon, but these are not considered in this paper). Simple process flow diagrams for the two studies are shown in Fig. 1 and 2. Both studies suggested that this would be the most cost-effective way to grow microalgae. The scale of production modelled by Campbell et al. $(2008,2011)$ was significantly smaller than that of Griffin \& Batten (2009) (a total pond area of 400 ha was assumed for the Campbell et al. model compared to 5,000 ha for the Griffin \& Batten model). Campbell et al. $(2008,2011)$ identified a number of sites in coastal regions of northern Queensland, northern Western Australia and South Australia where the necessary resources were available. In contrast, the larger land requirement modelled by Griffin \& Batten (2009) fixed the location to a coastal region near the South Australia town of Port Augusta, where both suitable land and a coal-fired power station was located. 
The primary production steps and key assumptions from the two sources are summarised in Table 1 . Note that Campbell et al. $(2008,2011)$ assume a higher oil (or triglyceride) content in the microalgae than Griffin \& Batten (2009) and a higher growth rate. However, one scenario in Campbell et al. $(2008,2011)-$ an microalgae

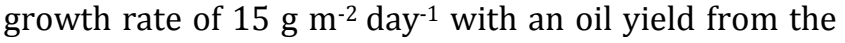
microalgae of $50 \%$ - yields similar overall oil yields $(7.5$ $\mathrm{g} \mathrm{m}^{-2}$ day $^{-1}$ oil production rate) to a scenario used in Griffin and Batten (2009) - an microalgae growth rate of $20 \mathrm{~g} \mathrm{~m}^{-2}$ day $^{-1}$ with an oil yield of $30 \%\left(6 \mathrm{~g} \mathrm{~m}^{-2}\right.$ day $\left.^{-1}\right)$. Consequently, these two scenarios will be used as the basis of comparison between the two economic studies.

\subsection{Summary of process steps used in Campbell et al.}

Algae are grown in raceway ponds using sea water as the growth medium. The total pond size is 400 ha. Carbon is supplied to the medium by bubbling flue gases from a power station through the medium. Two scenarios were investigated - an 'ideal' case and a 'realistic' case. In the ideal case, the microalgae growth (dry weight) is $30 \mathrm{~g} \mathrm{~m}^{-2}$ day $^{-1}$ (109.6 $\mathrm{t} \mathrm{ha}^{-1} \mathrm{yr}^{-1}$ ) and the power station is located adjacent to the ponds. In the realistic case (used in this paper for comparison with the results of Griffin \& Batten 2009) the growth rate was $15 \mathrm{~g} \mathrm{~m}^{-2}$ day $^{-1}$ and the power station was located 2.5 $\mathrm{km}$ from the ponds (thereby increasing the costs of transporting the flue gases to the ponds). The microalgae is harvested by means of flocculation in settling tanks, further concentrated by dissolved air flotation (DAF) and finally dewatered by centrifugation. Extraction of the oil is performed using a solvent extraction process. It is assumed that the recoverable oil from the microalgae is $50 \%$ of the microalgae mass. The oil is then transesterified to produce the biodiesel.

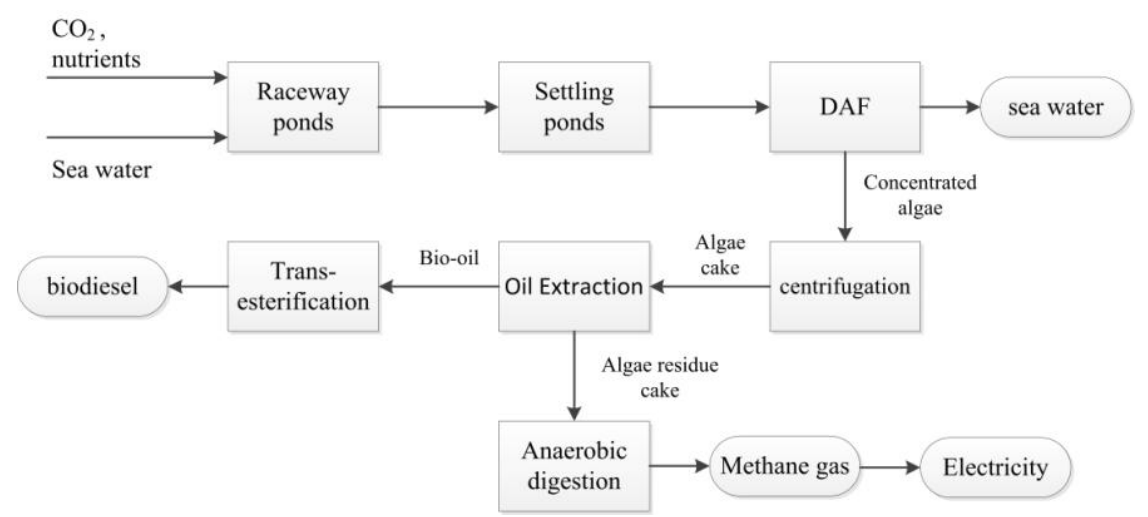

Fig. 1 Process diagram for production of biodiesel from microalgae used by Campbell et al. $(2008,2011)$

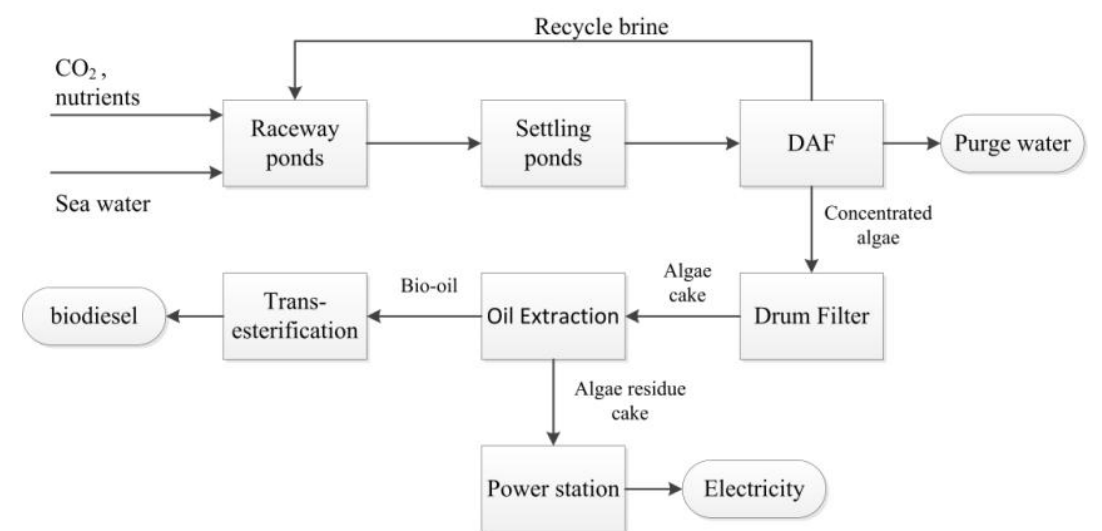

Fig. 2 Process diagram for production of biodiesel from microalgae used by Griffin \& Batten (2009)

Table 1

Key assumptions used

\begin{tabular}{lcc}
\multicolumn{1}{c}{ Assumption } & Campbell et al. & Griffin \& Batten \\
\hline Pond size (ha) & 400 & 5,000 \\
Salt concentration in growth medium ( $\times$ sea water) & 1 & 4 \\
Algae growth rate $\left(\mathrm{g} \cdot \mathrm{m}^{-2}\right.$.day-1) & 15 or 30 & 20 \\
Extractable oil (\%) & 50 & 30 \\
Algae concentration in growth ponds (mg.L ${ }^{-1}$ ) & 500 & 600 \\
Concentration of $\mathrm{CO}_{2}$ in flue gases (\%) & 15 & 14 \\
Uptake of flue gas $\mathrm{CO}_{2}$ by algae (\%) & 95 & 100 \\
\hline
\end{tabular}


The residual microalgae mass is fed into an anaerobic lagoon. Methane produced from the decomposing microalgae is recovered and then either; piped back to the power station for use as fuel, or; fed into electricity generators located at the pond site. The electricity is fed into the national grid. In the cost comparison provided here, the latter scenario of electricity generation is used.

\subsection{Summary of process steps used in Griffin \& Batten}

Microalgae are grown in raceway ponds using sea water as the growth medium. The salt concentration in the medium is four times that of sea water. The pond size is 5,000 ha. Carbon is supplied to the medium by bubbling flue gases from a power station through the medium, and the power station is located $50 \mathrm{~km}$ from the ponds. The assumed growth rate of microalgae is $20 \mathrm{~g} \mathrm{~m}^{-2}$ day $^{-1}$. The microalgae is harvested by means of flocculation in settling tanks, further concentrated by DAF and finally dewatered by a rotary drum. Extraction of the oil is performed using a combined solvent extraction and pressing process. It is assumed that the microalgae consist of $30 \%$ recoverable oil. The oil is then transesterified to produce the biodiesel and the residual biomass is fed into a power station located at the pond site.

\section{Results and Discussion}

\subsection{Comparison of capital costs}

Table 2 and Fig. 3 summarise the capital cost estimates from both sources. Note that cost estimates given in this paper have been updated from the original papers to USD in mid-2012. In comparing the costs from the two sources, it was necessary to combine some different cost components under the same heading.

The difference in total capital cost between the two sources was more than USD160,000/ha, with the Griffin \& Batten capital cost estimation exceeding that of Campbell et al by approximately 97\% (Griffin \& Batten 2009). This difference is the major cause of the discrepancy noted in the final calculated cost of the oil and biodiesel.

The capital cost item with the greatest difference between the two sources was the equipment used for harvesting and concentrating the microalgae. This difference is unsurprising as the cost of large-scale harvesting of microalgae is highly dependent on the physical properties of the microalgae. Campbell et al and Griffin \& Batten adopted similar processes for harvesting and concentrating the microalgae, namely primary harvesting using settling tanks then concentration by DAF. However, the cost predictions in Campbell et al. (2008, 2011) are based almost exclusively on work reported in Benemann \& Oswald (1996), which in turn used the data of Regan and Gartside (1984), Benemann et al. (1982), and Weisman
Table 2

Comparison of Australian capital costs (USD/ha)

\begin{tabular}{|c|c|c|c|}
\hline Capital item(s) & $\begin{array}{c}\text { Campbell } \\
\text { et al. } \\
(15 \\
\left.\text { g.m }^{-2} \text { day }^{-1}\right) \\
\end{array}$ & $\begin{array}{c}\text { Griffin \& } \\
\text { Batten } \\
(20 \\
\left.\text { g.m-2.day }^{-1}\right) \\
\end{array}$ & $\begin{array}{l}\text { Percent. } \\
\text { Diff. }\end{array}$ \\
\hline Land acquisition & 3,974 & 12,203 & $+207 \%$ \\
\hline $\begin{array}{l}\text { Site preparation and } \\
\text { pond construction }\end{array}$ & 11,923 & 16,271 & $+36 \%$ \\
\hline Mixing (paddle wheels) & 9,936 & 21,017 & $+112 \%$ \\
\hline $\begin{array}{l}\mathrm{CO}_{2} \text { supply \& } \\
\text { distribution }\end{array}$ & 24,146 & 15,729 & $-35 \%$ \\
\hline Water supply & 10,508 & 17,898 & $+70 \%$ \\
\hline $\begin{array}{l}\text { Harvesting and } \\
\text { concentration of } \\
\text { microalgae }\end{array}$ & 17,885 & 86,553 & $+384 \%$ \\
\hline $\begin{array}{l}\text { Dewatering of } \\
\text { microalgae and oil } \\
\text { extraction }\end{array}$ & 24,839 & 31,186 & $+26 \%$ \\
\hline Transesterification & 14,830 & 11,864 & $-20 \%$ \\
\hline Electricity generation & 18,211 & 59,322 & $+226 \%$ \\
\hline $\begin{array}{l}\text { Miscellaneous structures } \\
\text { and instrumentation, etc }\end{array}$ & 8,942 & 17,175 & $+92 \%$ \\
\hline $\begin{array}{l}\text { Nutrient supply and } \\
\text { waste treatment }\end{array}$ & 3,974 & - & $\mathrm{N} / \mathrm{A}$ \\
\hline $\begin{array}{l}\text { Engineering/Contingenci } \\
\text { es }\end{array}$ & 17,792 & 43,390 & $+144 \%$ \\
\hline Working capital & 5,453 & 6,418 & $+18 \%$ \\
\hline Total capital cost & 172,414 & 339,027 & $+97 \%$ \\
\hline
\end{tabular}

and Goebel (1987). Griffin \& Batten (2009) used data reported in Mohn (1988).

The capital cost item with the greatest difference between the two sources was the equipment used for harvesting and concentrating the microalgae. This difference is unsurprising as the cost of large-scale harvesting of microalgae is highly dependent on the physical properties of the microalgae. Campbell et al. (2008, 2011) and Griffin \& Batten (2009) adopted similar processes for harvesting and concentrating the microalgae, namely primary harvesting using settling tanks then concentration by DAF. However, the cost predictions in Campbell et al. $(2008,2011)$ are based almost exclusively on work reported in Benemann \& Oswald (1996), which in turn used the data of Regan and Gartside (1984), Benemann et al. (1982), and Weisman and Goebel (1987). Griffin \& Batten (2009); used data reported in Mohn (1988).

Assuming that these data sources are independent, the difference in costing may come from the different assumptions made about achievable settling rates. Unfortunately, actual settling rates on which the cost rates are calculated are elusive. Furthermore, the use of settling tanks reported in Benemann et al. (1982) involved the assumption that auto flocculation of the microalgae was achievable for primary settling, followed by settling in a secondary tank with the aid of flocculants. In Griffin \& Batten (2009), a more conservative approach is adopted, in which all flocculation requires the use of flocculants. It is clear from the source data that, without detailed data on the settling rates achievable for the microalgae, any cost estimation carries a high risk of inaccuracy. 
Another significant difference, in dollar terms, was the capital cost of the power generation units required to utilise the residual microalgae biomass after the extraction of oil. Campbell et al. assume that methane generated for anaerobic lagoons may be used by generators onsite. In contrast, Griffin \& Batten assumes the residual biomass is burnt in a power station constructed on site. This difference in the way the power stations operate accounts for about $25 \%$.

The cost of contingencies/engineering accounted for $15 \%$ of the total capital costs for both models but, due to the overall large difference in total capital cost between sources, results in a large absolute difference in costs.

Even the process by which the large amount of water is circulated through the microalgae ponds had a significant effect on the capital costs. Traditionally paddle wheels (and associated equipment) providing mixing in the raceway ponds. In Griffin \& Batten (2009), it was calculated that the costs of the paddle wheels were much higher than those reported elsewhere (Benemann \& Oswald 1996). This was due to the high cost of channel profiling beneath the wheels, which was not as significant in the other calculations.

It should be noted that both studies assumed that the pond channels required no special lining materials to be installed, implying that the ponds are sited on impervious ground. If lining material must be installed, this would significantly add to the capital costs. The process of transesterification, necessary to convert all bio-oil to a usable diesel, was based upon the costing available in Haas et al. (2006). Due to the higher production rate of oil assumed by Campbell et al, the capital costs are also higher.

\subsection{Comparison of Operating Costs}

Table 3 and Fig. 4 shows the operating cost estimates from the two sources using the same layout as used for Table 2 and Fig. 4 (note that the revenue stream from the sale of power is not included in the figure). It is evident that there are a number of operating costs from Campbell et al. that exceed that of the Griffin \& Batten estimates and vice-versa. By way of contrast, almost all the capital cost differences were due to the costs calculated by Griffin \& Batten (2009) significantly exceeding that of Campbell et al. (2008, 2011). Clearly, the major difference in total operating costs arises from the difference in the capital charge or amortization. Both Campbell et al. $(2008,2011)$ and Griffin \& Batten used $15 \%$ of the total capital costs for their capital charge. As Griffin \& Batten (2009)estimate much higher capital costs, this results in higher capital charges. This difference accounts for $84 \%$ of the total difference of operating costs. Another significant difference is due to the cost of flocculants which are higher in Griffin \& Batten due to the more conservative assumptions used (as already noted). These two items alone account for the total difference in operating costs.
Table 3:

Comparison of Australian operating costs (USD ha-1.yr-1)

\begin{tabular}{|c|c|c|c|}
\hline Operating item(s) & $\begin{array}{l}\text { Campbell } \\
\left(15 \mathrm{~g} / \mathrm{m}^{2} \cdot \mathrm{da}\right. \\
\left.\mathrm{y}^{1}\right)\end{array}$ & $\begin{array}{l}\text { Griffin \& } \\
\text { Batten } \\
\left(20 g^{-m^{-2}} \cdot \text { day }^{-1}\right)\end{array}$ & $\begin{array}{l}\text { Percent. } \\
\text { difference }\end{array}$ \\
\hline Power, mixing & 913 & 189 & -79 \\
\hline Power, water supply & 602 & 47 & -92 \\
\hline $\begin{array}{l}\text { Power, flue gas } \\
\text { supply }\end{array}$ & 272 & 245 & -10 \\
\hline Power, harvesting & 651 & 324 & -50 \\
\hline Power, other & 130 & - & -100 \\
\hline Nutrients & 1,789 & 5,615 & +214 \\
\hline Flocculants & 1,988 & 11,152 & +461 \\
\hline Labour & 5,961 & 895 & -85 \\
\hline Waste disposal & 1,988 & - & -100 \\
\hline $\begin{array}{l}\text { Microalgae } \\
\text { processing to } \\
\text { biodiesel }\end{array}$ & 5,662 & 11,542 & 104 \\
\hline $\begin{array}{l}\text { Electricity } \\
\text { generating costs }\end{array}$ & - & 1,853 & - \\
\hline Power credit & $-4,731$ & $-7,412$ & +57 \\
\hline $\begin{array}{l}\text { Insurance, } \\
\text { maintenance, tax, } \\
\text { etc. }\end{array}$ & 6,586 & 1,220 & -81 \\
\hline Capital charge & 22,700 & 45,006 & +135 \\
\hline $\begin{array}{l}\text { Total annual cost (oil } \\
\text { production)a }\end{array}$ & 42,012 & 64,984 & +92 \\
\hline $\begin{array}{l}\text { Total annual cost } \\
\text { (biodiesel } \\
\text { production) }\end{array}$ & 47,674 & 76,528 & +76 \\
\hline Cost of oil (USD/L) & 1.37 & 2.66 & $* 101$ \\
\hline $\begin{array}{l}\text { Total cost of } \\
\text { biodiesel (USD/L) }\end{array}$ & 1.59 & 3.19 & +101 \\
\hline
\end{tabular}

aOil production cost estimate assumes that transesterification is not required

\subsection{Difference in Oil Productivity}

It should be noted that the oil productivity in Campbell et al. $(2008,2011)$ (7.5 g m-2 day-1) is $25 \%$ higher than that used in Griffin \& Batten (2009) (6 g m2 day-1), which further increases the difference in cost of oil or biodiesel per unit volume.

\section{Other cost predictions for microalgae to oil production.}

A report from the US Department of Energy (USDoE, 2009), which is largely based on a presentation by Pienkos (2008) provides a brief summary of the cost estimates (based on the production of triglyceride) from a number of sources in other parts of the world.

Alabi et al. (2009) provide economic estimates of microalgae to biodiesel production using photosynthetic and fermentation methods to grow the microalgae. The key assumptions and cost comparisons of the different literature resources are collated in Table 4 and Fig. 5. These data provide cost estimates for a number of microalgae production configurations (including one from Benemann and Oswald (1996), some of which are based on raceway ponds and others on the use of photo-bioreactors (PBR). Note that the assumed microalgae productivity and oil content of the microalgae varies between 10-110 g.m ${ }^{-2}$.day ${ }^{-1}$ and 15$60 \%$ respectively, so the Australian assumptions fit well within this accepted range. 


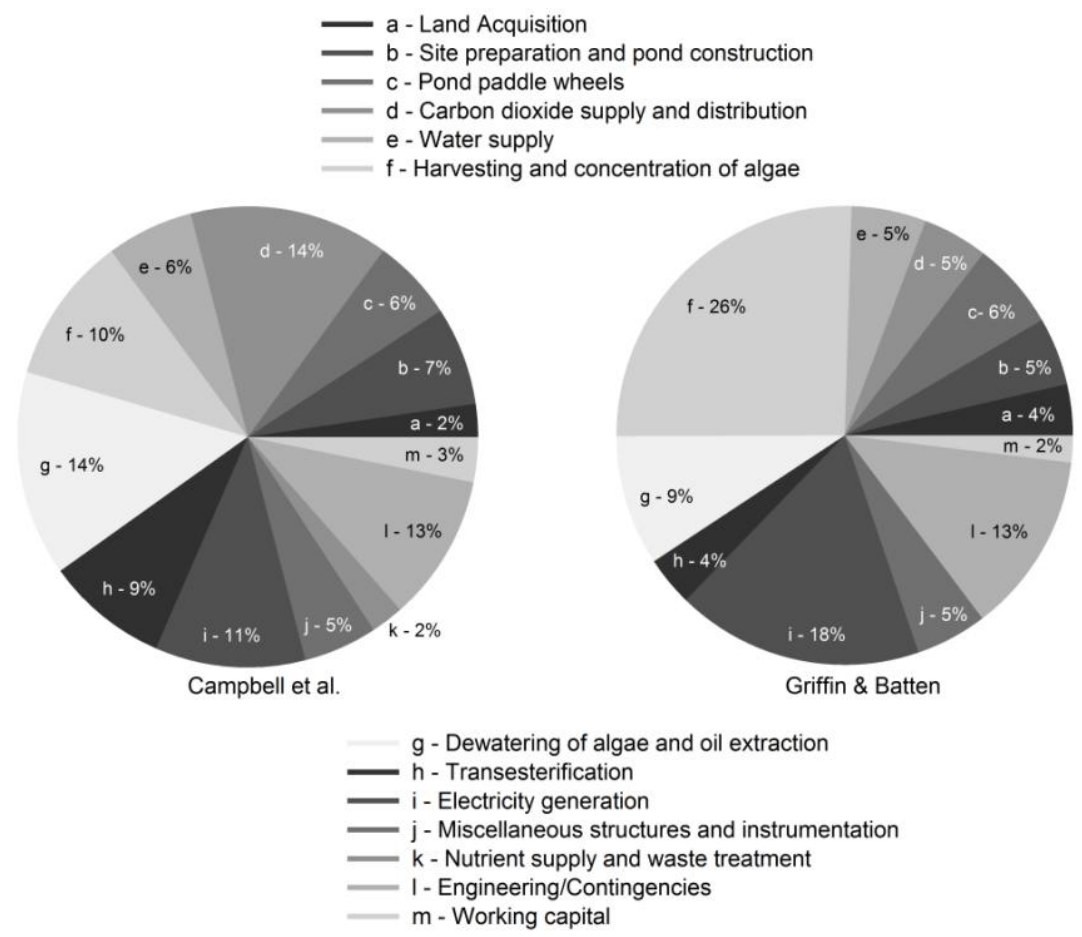

Fig. 3 Capital cost components from Campbell et al. $(2008,2011)$ and Griffin \& Batten (2009)

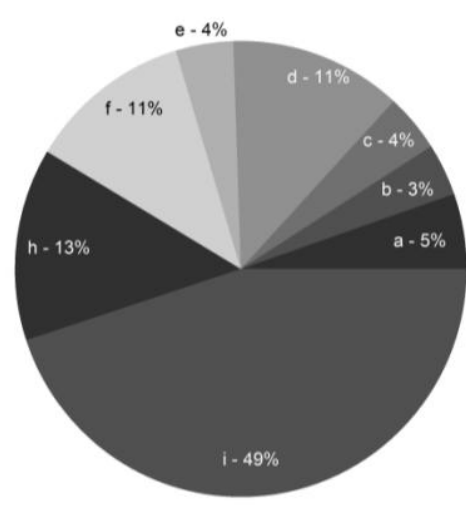

Campbell et al.

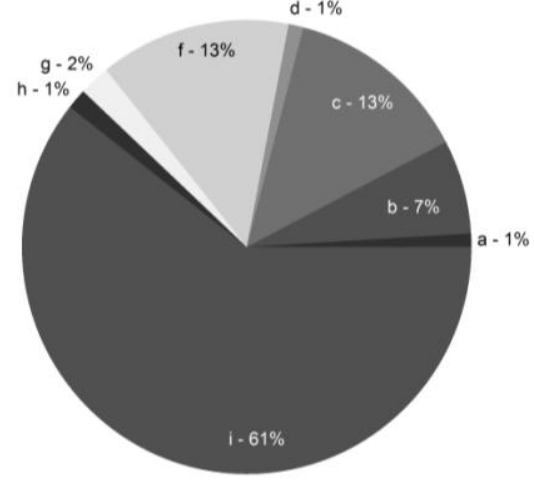

Griffin \& Batten

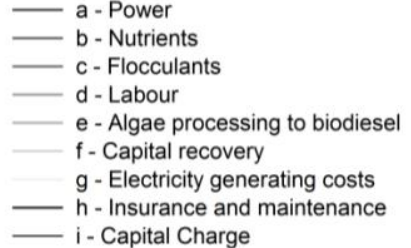

Fig. 4 Operating cost components from Campbell et al. and Griffin \& Batten

Though the cost of oil production varies greatly, with the majority of data falling between 3 and 30 USD/L, there are studies well outside this band. The cost predictions based on Benemann and Oswald are at the lowest end of the range at $\sim 0.34-0.52 \mathrm{USD} / \mathrm{L}$. This conforms to the cost estimates of Campbell at al., who estimated a cost of triglyceride of $0.62 \mathrm{USD} / \mathrm{L}$ (for an

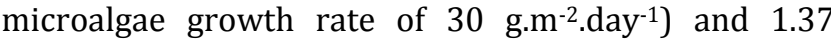

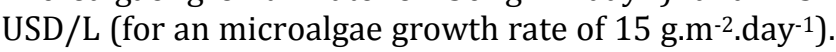

Griffin \& Batten (2009) estimated an oil cost of 2.94 USD/L.

The results of Alibi et al. (2009) and Amer et al. (2011) provide comparisons between the economics of raceway, PBR and fermentation methods for producing microalgae cells. The PBR method of producing microalgae is assumed to allow much higher productivity rates of oil rich microalgae species than possible with raceways; however this advantage is 
more than offset by the significantly higher capital costs of building a PBR facility. The capital recovery costs of the raceway operation comprises $49 \%$ of the annual operating budget (comparable with the results of Campbell et al. $(2008,2011)$ and Griffin \& Batten 2009) and, for a PBR facility, $63 \%$ of the annual operating costs. The Alibi et al. (2009) model use relatively low growth rates of microalgae for raceways and PBRs as the site of the proposed facilities is in the colder regions of the northern hemisphere (far outside the region identified by van Harmelen \& Oonk (2006) as optimum for microalgae growth). Thus the calculated oil costs are at the upper end of the range reported (see Fig. 5). In contrast, the model of Amer et al. (2011) agrees with the majority of models that open raceway ponds in a suitable climatic region provide the conditions for producing phototrophic microalgae at the lowest cost.

The advantages of the fermenter system are that the capital costs are significantly lower, with capital recovery comprising only $11 \%$ of the annual operating costs. The fermenter system's relatively low capital cost is due to the high concentration of microalgae cells that can be grown in the fermenter vessels. Alibi et al. (2009) assume that cell concentrations of $50 \mathrm{~g} / \mathrm{L}$ can be achieved. In PBRs and raceways, microalgae concentrations in the growth medium are limited to a maximum of about $0.5-0.6 \mathrm{~g} / \mathrm{L}$ (and experimentally have usually achieved much lower concentrations). At these values, the growth medium becomes so opaque that light cannot penetrate into the medium, with microalgae concentrations typically half this in commercial operations. Thus the fermenter system requires significantly less volume to achieve the required growth rate, and significantly less processing to separate the microalgae from the growth media; with concomitant reduction in capital investment. The major disadvantage of a fermenter system, however, is that the microalgae must be grown using carbohydrate as the nutrient source for carbon and for energy, which inevitably is reliant on the availability of large amounts of such material.

Stephens et al. (2010) provide an economic analysis for the production of biodiesel in which they identify two baseline scenarios - a base case in which an microalgae growth rate of 20 g.m ${ }^{-2}$.day-1 with an oil content of $25 \%$ by mass is achieved, and a projected case in which an microalgae growth rate of 50 g.m ${ }^{-2}$.day ${ }^{-1}$ with an oil content of $50 \%$ by mass is achieved. Their capital and operating costing were based on production methods using raceway ponds and conventional harvesting and oil extraction processes. These capital and operating costs are in the same range as those given in the previous studies. In the base case it was assumed that a high value product (HVP) may be extracted from the microalgae which provide the majority of the revenue. This revenue exceeds the total operating cost (including capital recovery) of the microalgae-to-oil process. In the projected case there is no assumption that a HVP is produced.

Table 4.

Cost estimates for microalgae to oil production (adapted from Pienkos 2008)

\begin{tabular}{|c|c|c|c|c|c|}
\hline & Scenario & Reactor Type & $\begin{array}{l}\text { Lipid yield } \\
\text { (wt\% of dry mass) }\end{array}$ & $\begin{array}{l}\text { Areal Dry Microalgae } \\
\text { Mass Yield } \\
\left(\mathrm{g} \mathrm{m}^{-2} \text { day }^{-1}\right)\end{array}$ & $\begin{array}{l}\text { Loan Period } \\
\text { (yrs) or Annual } \\
\text { capital cost }(\%)\end{array}$ \\
\hline Benemann & per ha basis & open pond & 50 & 30 & 5 yrs \\
\hline Benemann & per ha basis & open pond, $\max$ & 50 & 60 & 5 yrs \\
\hline NREL & Current case & open pond & 25 & 20 & 15 yrs \\
\hline NREL & Aggressive case & open pond & 50 & 40 & 15 yrs \\
\hline NREL & Maximum case & open pond & 60 & 60 & 15 yrs \\
\hline NMSU & current yield & open pond & 35 & 35 & 20 yrs \\
\hline NMSU & highest yield & open pond & 50 & 58 & 20 yrs \\
\hline Solix & Current & hybrid & $16-47$ & $0-24.5$ & Unknown \\
\hline Solix & Q2, 2009 & hybrid & $16-47$ & $30-40$ & Unknown \\
\hline Seambiotic/IEC, Israel & Best yield & open & 35 & 20 & Unknown \\
\hline Sandia & Raceway \& PBR & both & 35 & 20 & Unknown \\
\hline Bayer Tech Services & Germany & PBR & 33 & 52 & 10 yrs \\
\hline Bayer Tech Services & El Paso, TX & PBR & 33 & 110 & 10 yrs \\
\hline General Atomics & 100 acres & open/hydrid & unk & unk & Unknown \\
\hline Cal Poly, Case 1 & 100 ha & $\begin{array}{l}\text { Wastewater } \\
\text { treatment } \\
\text { digester }\end{array}$ & 25 & 20 & 8 yrs \\
\hline Tapie \& Bernard & 10 ha & T-PBR & 35 & 20 & 5 yrs \\
\hline Alabi et al.(2009) & 400 ha & raceway & 15 & 9.38 & $14 \%$ \\
\hline Alabi et al. (2009) & 400 ha & PBR & 25 & 15.3 & $14 \%$ \\
\hline Alabi et al. (2009) & $1,200 \mathrm{~m}^{3}$ & fermenter & 50 & $\mathrm{~N} / \mathrm{A}^{\mathrm{a}}$ & $14 \%$ \\
\hline Amer et al. (2011) & 500 & pond & 40 & 23.8 & 15 yrs \\
\hline Amer et al. (2011) & 500 & PBR & 40 & 39.6 & 15 yrs \\
\hline $\begin{array}{l}\text { Campbell et al. (2008), } \\
\text { (2011) }\end{array}$ & 400 ha & raceway & 50 & 15 & $15 \%$ \\
\hline $\begin{array}{l}\text { Griffin and Batten } \\
(2009)\end{array}$ & 5,000 & raceway & 30 & 20 & $15 \%$ \\
\hline
\end{tabular}

a $50 \mathrm{~g} \mathrm{~L}^{-1} \mathrm{day}^{-1}$ cell production rate in fermenter is assumed 


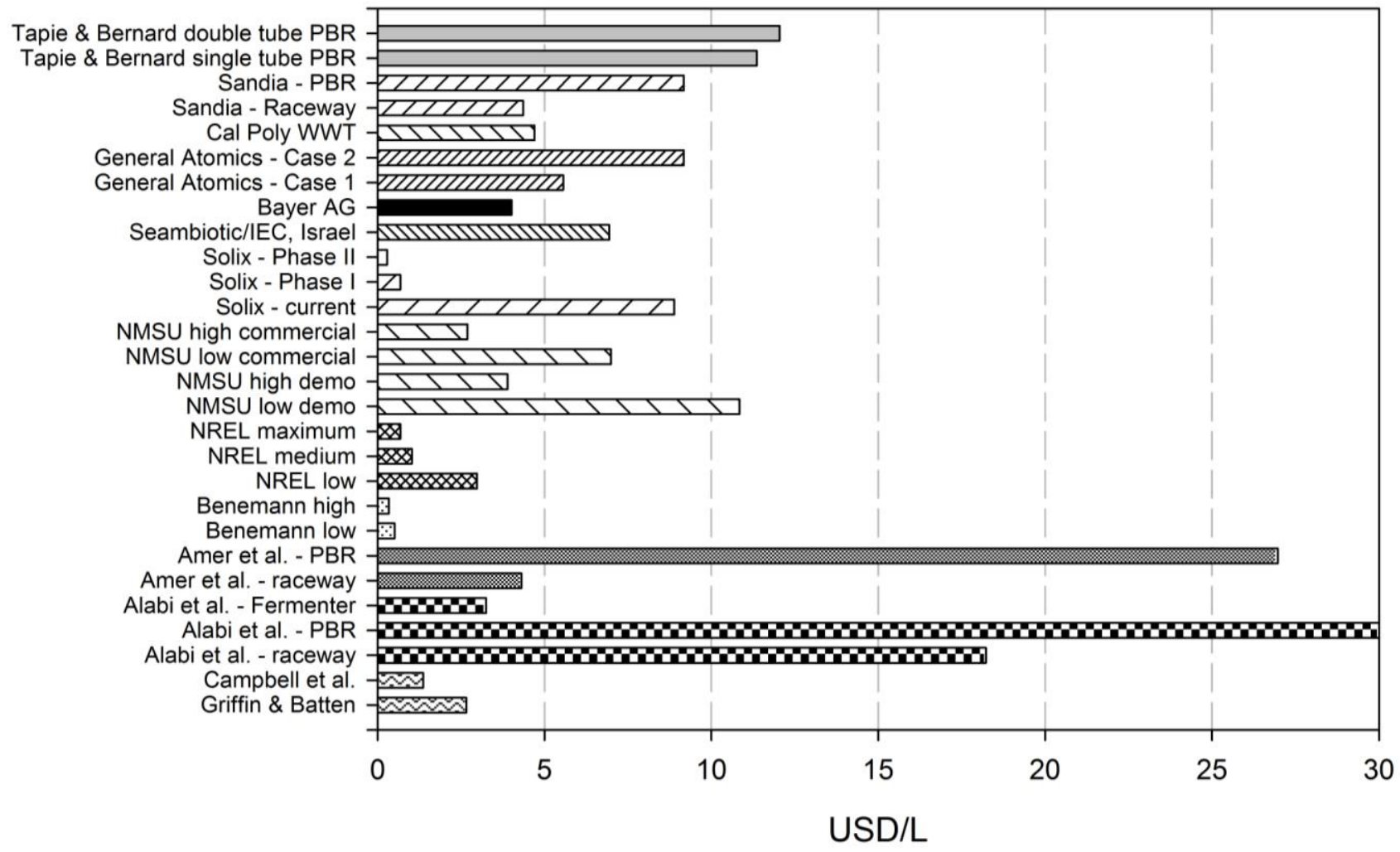

Fig. 5 Cost estimates for microalgae to oil production (adapted from USDoE, 2009; Pienkos, 2008)

However, values for the residual biomass (i.e. the microalgae after the oil is extracted) are set at levels that provide revenue that also exceeds the total operating cost (including capital recovery) of the microalgae-to-oil process. Thus, in both scenarios a cost of oil production calculation cannot be calculated from the data presented by the authors' paper, as the scenarios used show any oil revenues would be pure profit. This highlights an issue that has also been indicated in the research by Campbell et al. (2008, 2011) and Griffin \& Batten (2009); the value of the microalgae biomass is such that it may be better directed to alternative uses than the production of oil. Furthermore, the economic models of Gallagher (2011) predict that, for bio oil or biodiesel production to be viable, significant government tax-breaks or subsidies will be required.

\section{Conclusions}

It is clear from the bilateral comparison between the cost estimates that there are a significant difference in the calculated costs of producing oil (triglycerides) or biodiesel, even under almost identical conditions. The bottom-line economic costs calculated from the two studies (Campbell et al. 2008, 2011; Griffin \& Batten, 2009) gave predictions of USD1.59/L and USD3.19/L respectively for the production of biodiesel. The lower cost of USD1.59/L implies that Australian biodiesel sourced from microalgae could be imported economically into Asia. However, the fact that the two cost estimates differ by a factor of 2 indicate that there is considerable uncertainty as to the economic feasibility of such processes. This is reinforced by the significant variation in cost estimates calculated by other researchers for locations in a number of different countries, with the upper and lower limits varying by more than a factor of 10 .

A major impediment to the economic viability of microalgae-to-oil processing are the large capital costs all economic analyses have shown that recovery of capital costs contribute about $50 \%$ of the annual operating costs. Processing models to reduce the relative costs of capital rely on using carbon sources that may not be readily available. Therefore the future investment in microalgae-to-oil processes may be dependent, at least on the short term, on government subsidies to allow a viable industry to establish.

\section{References}

Alabi, O.A.; Tampier, M; Bibeau, E. (2009) Microalgae technologies and processes for biofuels/bioenergy production in British Columbia: Current technology. suitability and barriers to production. Final report: British Columbia Innovation Council, 63p.

Batten, D.F., Campbell, P.K., Threlfall, G. (2011) Resource Potential of Algae for Sustainable Biodiesel Production in the APEC Economies. Report prepared for the APEC Energy Working Group under EWG 18/2009, Document no. APEC\#211-RE-01.9, 35 p. (can be downloaded at http://www.egnret.ewg.apec.org /reports/index.html) 
Benemann, J.R.; Goebel, R.P.; Weissman, J.C.; Augenstein, D.C. (1982) Microalgae as a source of liquid fuels. Final Report, U.S. Department of Energy, $202 \mathrm{p}$.

Benemann, J.R; Oswald, W.J (1996). Systems and Economic Analysis of Microalgae Ponds for Conversion of $\mathrm{CO}_{2}$ to Biomass. Final Report, Pittsburgh Energy Technology Center

Campbell, P.K; Beer, T.; Batten, D. (2008) Greenhouse Gas Sequestration by Algae - energy and greenhouse gas life cycle studies. in Proc. 6th Australian Life-Cycle Assessment Conference, Melbourne.

Campbell, P.K., Beer, T and Batten, D. (2011) Life Cycle Assessment of Biodiesel Production from Microalgae in Ponds. Bioresource Technology, 102, 50-56: doi:10.1016/j.biortech.2010.06.048

Griffin, G.J; Batten D.F. (2009) The Economics of Producing Biodiesel from Micro-Algae in Australia. Proceedings of Bioenergy Australia conference, 8-10 December 2009, Gold Coast, Queensland, Australia.

Haas, M.J., McAloon, A.J., Yee, W.C., Foglia, T.A. (2006) A process model to estimate biodiesel production costs. Bioresourse Technology, 97, 671-678

Mohn, F.H. (1988) Harvesting of micro-algal biomass. in Borowitzka, M.A. \& Borowitzka, L.J. (eds), Micro-algal biotechnology, Cambridge University Press, Cambridge, Chapter 15
Pienkos, P. Historical Overview of Algal Biofuel Technoeconomic Analyses. DOE Algal BiofuelsWorkshop, University of Maryland, December 2008, http://purl.access.gpo.gov/GPO/LPS117182. Accessed on July 2010

Regan, D.L; Gartside, G. (1983) Liquid Fuels from Micro-Algae in Australia, (CSIRO, Melbourne, 1983).

Stephens, E., Ross, I.L., King, Z., Mussgnug, J.H., Kruse, O., Posten, C., Borowitzka M.A., Hankamer, B., 2010. An economic and technical evaluation of microalgal biofuels. Nature Biotechnology, 28, 126128

Van Harmelen, T. \& Oonk, H. (2006) Microalgae Biofixation Processes: Some Applications and Potential Contributions to Greenhouse Gas Mitigation Options. Report prepared for the International Network on Biofixation of $\mathrm{CO}_{2}$ and Greenhouse Gas Abatement with Microalgae, TNO, Apeldoorn, 45p.

USDoE (2009) National Algal Biofuels Technology Roadmap. US Department of Energy Biomass Program

Weismann, J.C. \&Goebel, R.P (1987) Design and Analysis of Pond Systems for the Purpose of Producing Fuels. Final Report, Solar Energy Research Institute., Golden, CO, SERI/STR-231-2840 